\title{
SURVEY METHODS FOR SEISMIC VULNERABILITY ASSESSMENT OF HISTORICAL MASONRY BUILDINGS
}

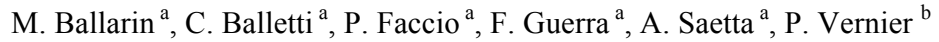 \\ ${ }^{\mathrm{a}}$ DACC; ${ }^{\mathrm{b}}$ Laboratorio di Fotogrammetria, Sistema dei Laboratori, \\ Università Iuav di Venezia, Santa Croce 191, 30135 Venezia, Italy - (martinab, faccio, guerra2, saetta, vernier)@iuav.it
}

KEY WORDS: Earthquake, Laser scanner, Cultural Heritage, Camera degli Sposi, Mantegna

\begin{abstract}
:
On $20^{\text {th }}$ and $29^{\text {th }}$ of May 2012, two powerful earthquakes struck northern Italy. The epicentres were recorded respectively in Finale Emilia (magnitude 5.9 Ml) and Medolla (magnitude 5.8 Ml) in the province of Modena, though the earthquake was formed by a series of seismic shakes located in the district of the Emilian Po Valley, mainly in the provinces of Modena, Ferrara, Mantova, Reggio Emilia, Bologna and Rovigo. Many monuments in the city of Mantova were hit by the earthquake and, among these, Palazzo Ducale with the well-known Castello di San Giorgio which host the noteworthy "Camera degli Sposi". This building, the most famous of the city, was so damaged that it was closed for more than one year after the earthquake. The emblem of the Palace and Mantova itself, the previously cited "Camera degli Sposi" realized by Andrea Mantegna, was damaged and all the economic and social life of the city was deeply affected. Immediately after the earthquake, the Soprintendenza per i Beni Architettonici e Paesaggistici of Brescia, Cremona and Mantova establish an agreement with the University Iuav of Venice, requiring an analysis and assessment of the damage in order to proceed with the development of an intervention project. This activity turned out to be very important not only from the point of view of the recovery of the architectural and artistic heritage but also because the city's economy is based primarily on tourism. The closure of one of the most important monuments of Mantova has led to a significant and alarming decline in the government income.
\end{abstract}

\section{INTRODUCTION}

Cultural Heritage constitutes a fundamental resource for all Countries, even in economic terms, as it can be considered an extraordinary tourist attraction. This is particularly true for Italy, which is one of the Countries with the richest artistic heritage in the world. For this reason, restoration becomes an essential step towards the conservation and therefore valorisation of architecture.

But, in recent years, our cultural heritage has often been hit by earthquakes that have affected the Italian territory: just considering the last decade, in 2009 the city of L'Aquila has been completely destroyed; in 2012 a series of tremors have affected the Emilia Romagna, hitting not only the heritage of many cities, but also the economy of the affected areas; in 2016, instead, it is the center of Italy to be more damaged with the destruction of several places including the cities of Accumoli and Amatrice.

An immediate documentation is necessary to shoring up and protect the damaged structures (Adami, 2016), before any restoration and reconstruction intervention.

It is clear that the seismic vulnerability assessment of historical masonry buildings requires an accurate knowledge of the palace, achieved through historical analysis, geometric survey of damage, identification of the transformation stages and constructive elements, by a material-constructive survey. This phase, which can be performed with different levels of accuracy, allows adopting different mechanical models to describe the behaviour of the building under dynamic actions and to choose the most suitable method of analysis to evaluate its safety regarding the seismic action of the reference site, defined according to the nominal design life and the classes of use.
Therefore an adequate knowledge of the historical building (original characteristics, changes due to aging, anthropogenic alterations and seismic events) represents the fundamental prerequisite not only for a reliable seismic safety assessment but also for the following design phase of an effective intervention for seismic improvement.

The path of knowledge involves the following activities, carried out not sequentially but through an integrated manner:

- the identification of the building, its location in relation to particular areas of seismic risk and with the surrounding urban context (isolated non-isolated);

- the geometric survey of the present state of conservation, documenting possible cracking and deformation phenomena; - the identification of the sequence of construction phases, from the hypothetical original configuration to the current one;

- the identification of the elements constituting the resistant organism, in the matter and constructive sense, with a strong focus on construction techniques, details and connections between elements;

- material identification, their state of degradation, of their mechanical properties;

- subsoil and foundation structures' knowledge, referring also to the changes occurred over time and possible damages.

This paper focuses on our experience in this context that allows us to reach a complete knowledge of the Castle of San Giorgio in Mantova. Because of the earthquake of May 2012, the Castle presented a series of structural damages (Fratus de Balestrini, 2013). On the occasion of its upcoming re-opening to the public, the Soprintendenza per i Beni Architettonici e Paesaggistici per le province di Brescia, Cremona e Mantova has requested an analysis and evaluation of the damages for the development of an intervention project.

As stated above, a special attention was given to the "Camera degli Sposi", also known as the Camera picta ("painted 
chamber"). It is a frescoed room, with illusionistic paintings by Andrea Mantegna, located in the northeast tower of the Castle. It was painted between 1465 and 1474 and commissioned by Ludovico Gonzaga, and it is well-known for the use of trompe l'oeil details and for the decoration of its ceiling.

The seismic shakes damaged the wall decorated with the "Scena della Corte" ("Court Scene"), above the chimney, re-opening an old crack that had to be analysed, in order to understand whether the damage was structural or just superficial. The diagnostic analyses constitute a fundamental prerequisite for the elaboration of any kind of intervention or restoration in any architectural, artistic or archaeological framework.

\section{DOCUMENTATION}

\subsection{The survey}

In emergency contexts that affect built heritage, Geomatics techniques enable the demands of documentation, risk assessment, management, in relation to danger condition (Chiabrando, 2017).

The survey of areas devastated by earthquakes presents some specific characteristics that differentiate it from the conventional schemes and standardized methods traditionally used. Every situation is a case in itself and requires the intervention and the integration of methods and tools that operate with heterogeneous precision but somehow have to communicate with each other within a single general reference system. In many cases buildings present serious damages that modify their shape, but sometimes collapses occur and there are only ruins. In such situations the references previously considered as fundamental for the design and the execution of a survey, are completely lost (Buttolo, 2011a; Buttolo, 2011b).

To obtain a description of the conservation state of the Camera, non-invasive integrated survey techniques were applied. The purpose of the present study is the definition of a methodology able to support the need of a rapid restoration intervention. In order to acquire the necessary data for the damage evaluation, we used three different kinds of laser scanners. These were chosen according to the dimension of the object that had to be surveyed. All the data acquired by these scanners were georeferenced in the same reference system, defined through a topographic network, measured with a topographic Total Station Leica TCR 1103

Given the complexity of the survey, we had to use a closed loop consisting of control points materialized on the ground both outside and inside of the Castle: the damage that had to be studied was located on one of the walls of the northern tower, therefore we needed to link the inside and the outside in the same reference system, in order to fully analyse the crack.

From the 15 topographic stations, three-dimensional coordinates of all the targets required for the laser scanning survey were detected. The observations were adjusted with least squares method, using MicroSurvey Starnet.

Since the signalization had already been prepared for all instruments, in the later phase of data acquisition the work was carried out by four different teams that worked at the same time. In this way, each team worked independently and it was possible to considerably decrease the time of data acquisition; a fundamental task in an emergency situation.

The first team, working with the total station, established the general topographic reference system and acquired the 3D coordinates of the targets for the laser scanning survey. From every point of the network the coordinates of all visible targets were acquired. In this way, every point has been measured by at least two stations: this is essential to generate visible redundancy in the data.
The second and the third team worked on the survey of the exterior and interior (figure 1-2) of the tower and the visitors' path, with two laser sensors based on the measurement of distance. Those instruments can be considered as automated total stations that measure horizontal and vertical angles and the distance between tool and surface, allowing the calculation of $3 \mathrm{D}$ coordinates of all points detected by the laser on the surface of the object to be scanned.

The second team, with the Riegl LMS-Z 390i (www.riegl.co.at), TOF technology based, focused on the acquisition of threedimensional data on the external walls of the north tower: 4 coloured scans were performed, in order to define the digital shape in the space of the external surfaces of the tower. With the same laser scanner point clouds for the entire Camera degli Sposi were also acquired.

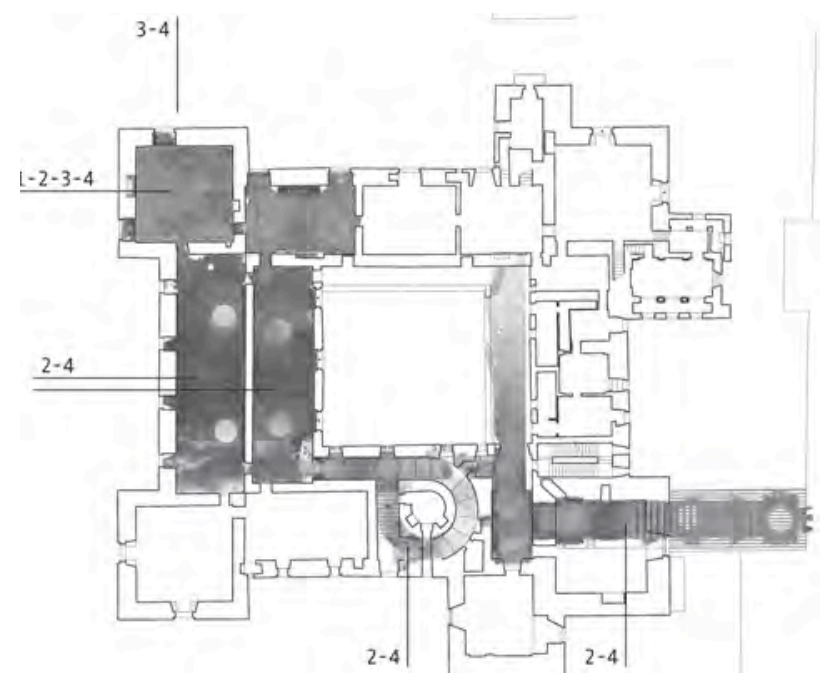

Figure 1. Plan of the documented rooms in the emergency survey

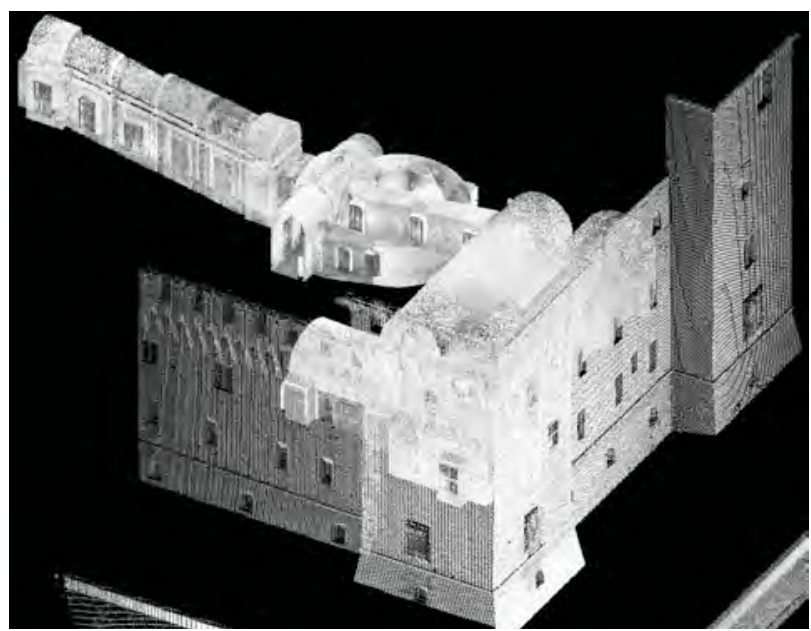

Figure 2. View of the dense point cloud

The third team worked with the phase shift measurement Faro Focus 3D laser scanner (www.faro.com), and performed 24 scans of the path that from of the Scalone di Enea leads to the Camera degli Sposi.

Detailed scans (figure 3) of the damage in the Camera degli Sposi were acquired with the range camera Minolta Vivid 9i, a non-contact tool measurement system based on triangulation (www.konicaminolta.eu). 
40 detailed scans of the crack on the wall called "della Corte", were acquired, in order to obtain the complete shape of the damage along the wall and to have a measurement of any deviation from the mean plane of the surface of the area affected by the crack.

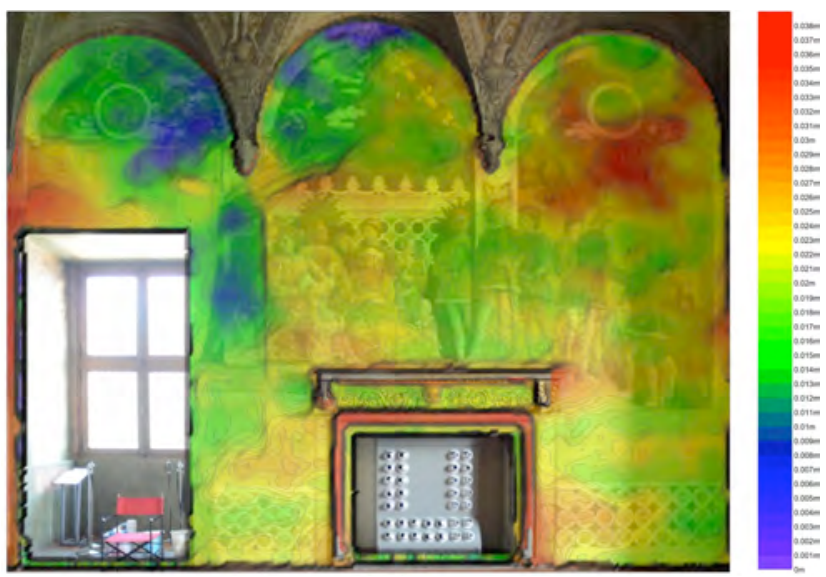

Figure 3. Range map in false colour of the north wall of the Camera degli Sposi

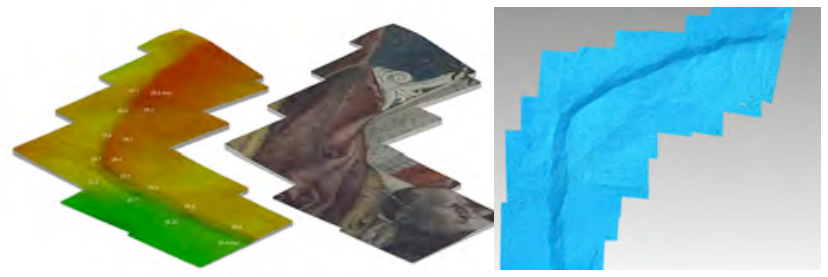

Figure 4. Detailed DSM of the crack

\subsection{Data processing}

Point clouds registration was carried out in the same general reference system given by the topography network.

Through management software acquisition tools (RiSCAN PRO for Riegl, SCENE for Faro), individual scans were aligned through a methodology known as "georeferencing on target" (topographic control points). This methodology requires the use of the topographic data acquired with the total station (the 3D coordinates of the centers of the targets) to record the various clouds of points in the same reference system.

At the end of this process the result is a point cloud constituted by millions of points that describes the shape in the space of all surfaces detected in an almost continuous, but in a still discrete way. From this point on, it is possible to extract all the various kind of representations, depending on the purpose of the survey itself.

Scans acquired with the range camera were georeferenced in a different way. Just because triangulation baser scanners do not require the use of target (they are used only in a few cases with completely smooth or monochrome surfaces), ICP algorithms (Iterative Closest Point) were used for the alignment of the recorded meshes.

During the data acquisition, as the scans were acquired, a cloud on cloud alignment was performed, using remarkable points or discontinuity of colour on the scanned surfaces. ICP algorithms are able to mimimise point-by-point (given at least three homologous points on two contiguous scans) the distance between the reference surface and the one that is considered as free to move. In this way, at the end of the acquisition phase, all the scans are already aligned in a local reference system. To set this in the global topographic reference system a rototraslation was performed, using 3D coordinates of points taken from point clouds acquired with the terrestrial laser scanner.

\subsection{Data representation}

The work has focused primarily on the Camera degli Sposi and in particular on the damages on the north wall also known as "della Corte".

Since all the scans were registered in the same reference system, it was possible to immediately verify the thickness of the perimeter wall of the tower.

Secondly, orthophotos from the inside and outside walls were overlapped to check if the internal damage had affected the outside area as well: it was soon clear that the damage occurred on a bricked up window on the wall.

Because of this, the outer wall was no longer continuous: this caused the earthquake to generate a different movement between the body of the tower and the bricked up window; the previous crack re-opened.

However, the observations derived from this first analysis did not give a complete picture of the situation. Other representations were then obtained with the false colour depth mapping of the damage. As we did for the orthophotos, the two images were overlapped and compared. The operations just described have shown that the external wall did not present considerable discontinuities and therefore that the earthquake had not caused harmful effects. On the other hand, the internal wall, in correspondence to the damage, presented deviations of up to $5 \mathrm{~cm}$ between the body of the tower and the infill.

Two fundamental considerations can therefore be made. The first is that, due to the different behaviour between inside and outside walls, there is definitely a gap. The second consideration concerns the discontinuity of the inner wall: after a careful analysis of the data obtained, it emerged that the damages had not been caused by the earthquake of May 2012, but by an earthquake which occurred in previous centuries. As can be seen in the DSM (Digital Surface Model) obtained from the point clouds, the infill had a forward movement of even 5 $\mathrm{cm}$ in the top area, causing significant damage, which was later plastered and repainted (figure 3-4). Most probably, the Emilian earthquake just caused a superficial damage to the plaster of the previous crack.

As a result of considerations explained in this research, Mantegna's fresco has now been restored to its original beauty. For what concerns the path from the Scalone di Enea to the Camera degli Sposi, technicians were provided with orthophotos of plans, fronts and sections, useful for subsequent re-design or analysis of the cracks in the walls.

\section{THE VULNERABILITY ASSESSMENT AND RESTORATION INTERVENTION OF THE NORTH- EAST TOWER}

\subsection{The interpretative model of the North-East tower}

The chance of giving back the Camera degli Sposi to the city of Mantova, with the reopening of Palazzo Ducale to the tourists, required the preliminary assessment of seismic vulnerability of the North-East Tower, hosting this famous Camera degli Sposi, Thanks to the accurate survey of both the geometry and damage state (i.e. crack pattern and out-of-plumbs), the FEM models of the North-East Tower and of the entire San Giorgio Castle have been realized (figure 5).

Then, a number of analyses have been carried out, starting from the static linear analysis up to the evaluation of local mechanisms which could activate due to probable seismic events expected in the Mantova site. 

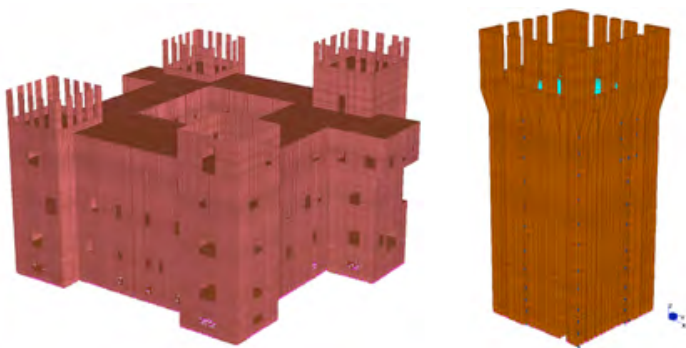

Figure 5. (a) FE model of San Giorgio Castle and (b) of the North East Tower

As an example, figure 6 shows the scheme of the local mechanism which involve the rotation of the whole North-East Tower around a side at the base. The load multiplier results:

$$
\alpha=\frac{\sum_{i=1}^{n} W_{i} \cdot \frac{s_{i}}{2}+\sum_{i=1}^{n} F_{V i} \cdot d_{V i}+\sum_{i=1}^{n} P_{S i} \cdot d_{i}+\sum_{i=1}^{n} T_{i} \cdot h_{i}-\sum_{i=1}^{n} F_{H i} \cdot h_{V i}-P_{H} \cdot h_{i}}{\sum_{i=1}^{n} W_{i} \cdot y_{G i}+\sum_{i=1}^{n} F_{V i} \cdot h_{V i}+\sum_{i=1}^{n} P_{S i} \cdot h_{i}}
$$

and, in this case, the capacity / demand ratio resulted greater than 1.00 , so demonstrating that this particular mechanism is satisfied.

In figure 7, it is shown the mechanism which involves the upper corner part of the tower, whose identification has been possible thanks to the accurate analysis of the crack survey and by performing a modal analysis which allowed to identify the proper vibration mode.

The capacity/demand ratio in this case resulted equal to 0.27 , underlining a high vulnerability of the tower with respect to such a mechanism. Similarly, the local mechanism involving the overturning of the single facades around their bases, does not result satisfied.
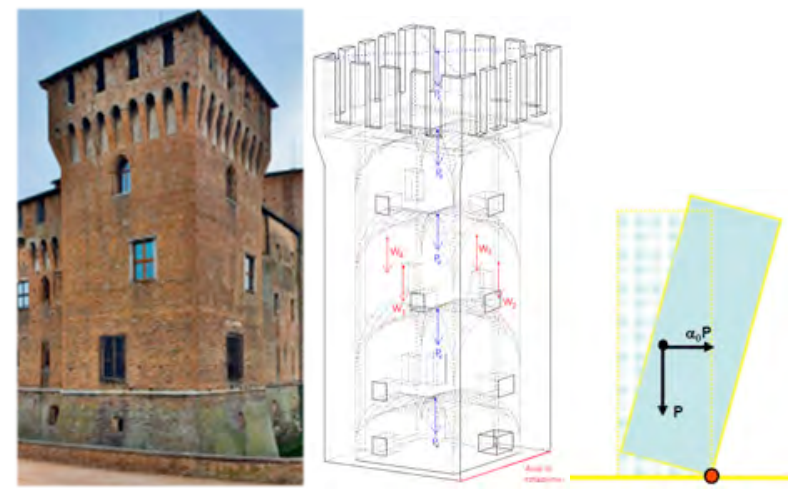

Figure 6. (a)The North-East tower; (b) The loads involved in the local mechanism; (c) the scheme of the local mechanism
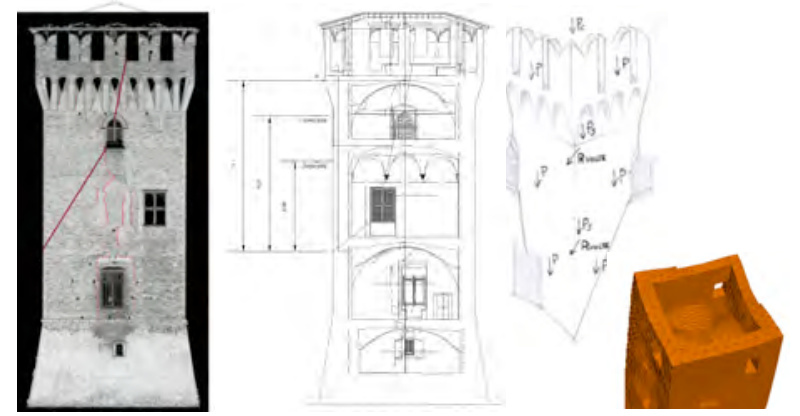

Figure 7. (a)The North-East tower; (b) The section; (c) the scheme of the local mechanism; (d) the corresponding vibration
The outcomes of these analyses evidenced the need of specific restoration interventions, mainly aimed to reduce the vulnerability of local mechanisms. Therefore a restoration project, prescribing the adoption of steel hoops and ties at the floor levels of the tower was developed by prof. Paolo Faccio.

Finally, a FE model of the north wall of the Camera degli Sposi, i.e. the "della Corte" wall, was developed. The main aim was to investigate the vulnerability of this wall, where the famous Mantegna's fresco is located, caused by the presence of the previously cited chimney.

Actually, the preliminary analyses carried out for this element showed the high vulnerability of the curtain wall in correspondence of the chimney, figure 5 , also demonstrated by the results of the survey, which have shown the deviations from the mean plane of the surface of such wall (i.e. see figure 3 ).
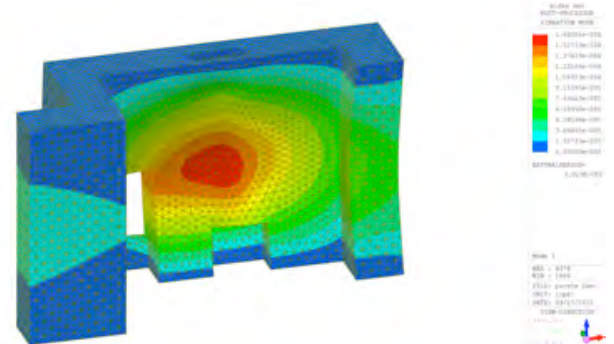

Figure 8. Preliminary results of FE analyses of "della Corte" wall
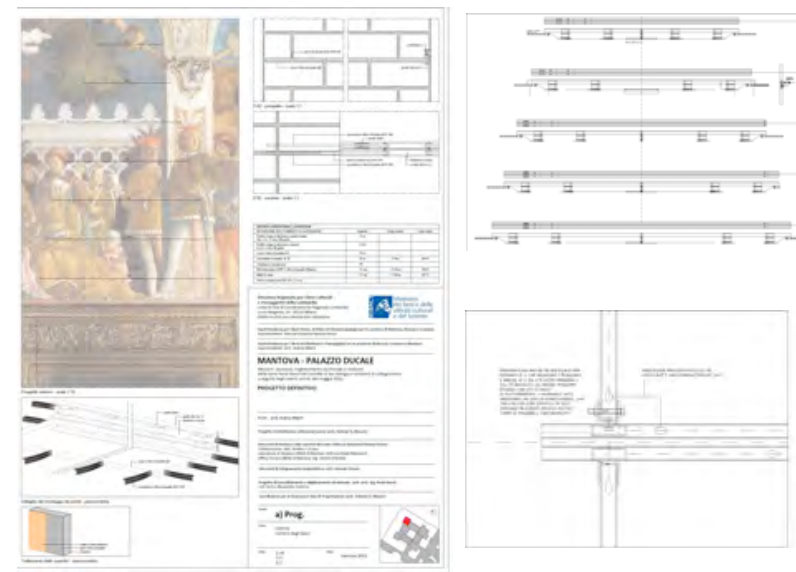

Figure 9. Restoration project
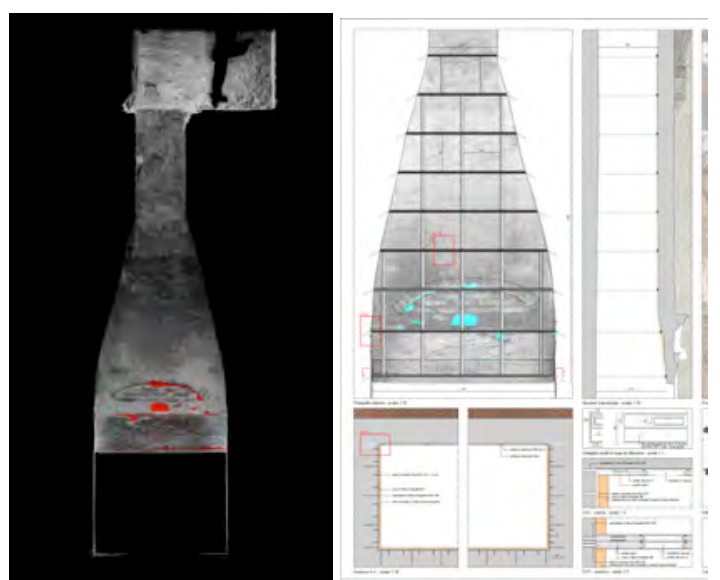

Figure 10. (a) laser scanner survey of the internal side of the chimney; (b) view of the restoration project mode 


\subsection{The restoration project of the "Camera degli Sposi"} chimney internal wall

Based on the results of the numerical analyses, a restoration project for the chimney internal wall was developed by prof. Paolo Faccio (figure 9).

This project prescribed the use of steel and basalt elements positioned in correspondence of the internal side of the chimney, by using the existing discontinuities evidenced by the laser scanning survey, figure 10 . In this way the realization of the intervention minimized the actions on the curtain wall where the famous painting is located.

\section{CONCLUSIONS}

This paper shows the importance of a multidisciplinary approach in an emergency context.

Geomatics instruments and methods used in this research are not innovative, but they represent a consolidate approach in the field of Cultural Heritage documentation, and ensure the accuracy required in this type of investigation (Achille et al., 2015; Ballarin et al., 2013). It is clear that Geomatics allows the definition of a standard procedure that can be used in these critical situations, based on the creation of multiresolution morphological maps of deformation (considering of the quantity of damage) obtained by the use of multiple laser scanners with different characteristics and precisions.

With this procedure it is possible, using the data acquired in situ, integrated with thematic restoration analyses, to highlight the damage mechanisms in the structure and to check the hypothesis of damage to establish a protocol for a rapid intervention.

In this peculiar application, as shown by the structural analysis conducted and supported by the survey data, the Castle is characterized by its specific state of conservation. The detected crack patterns were due to static nature causes, decisive for the response of the system, that represent an additional element of vulnerability. The pre-existing cracks (as in the Camera degli Sposi) constitute a preferential path for lesions in case of an earthquake, and facilitate the activation of local mechanisms of collapse.

\section{REFERENCES}

Achille, C., Adami, A., Chiarini, S., Cremonesi, S., Fassi, F., Fregonese, L., Taffurelli, 2015. L. UAV-based photogrammetry and integrated technologies for architectural applications Methodological strategies for the after-quake survey of vertical structures in Mantua (Italy). Sensors, 15, 15520-15539

Adami, A., Chiarini, S., Cremonesi, S., Fregonese, L., Taffurelli, L., Valente, M. V., 2016. The survey of Cultural Heritage after earthquake: the case study of Emilia - Lombardia in 2012. Int. Arch. Photogramm. Remote Sens. Spatial Inf. Sci., XLI-B5, 161-168, doi:10.5194/isprs-archives-XLI-B5-1612016.

Ballarin, M., Buttolo, V., Guerra, F., and Vernier, P., 2013. Integrated surveying techniques for sensitive areas: San Felice sul Panaro. ISPRS Ann. Photogramm. Remote Sens. Spatial Inf. Sci., II-5/W1, 19-24, doi:10.5194/isprsannals-II-5-W1-19-2013, 2013.

Buttolo, V., Geremia, E., Guerra, F., 2011a. Rilievo Laser Scanning e Analisi dei dati di facciate colpite dal sisma. Proceedings of V-Earth Sim, Virtual Earth Simulation, L'Aquila.
Buttolo, V., 2011b. Il sisma aquilano: rilievo laser scanner delle architetture e interpretazione dei dati. Proceedings of Asita 2011, Parma.

Chiabrando, F., Sammartano, G., and Spanò, A., 2017. A comparison among different optimization levels in $3 \mathrm{~d}$ multisensor model. A test case on emergency context: 2016 italian earthquake. Int. Arch. Photogramm. Remote Sens. Spatial Inf. Sci., XLII-2/W3, 155-162, doi:10.5194/isprs-archives-XLII-2W3-155-2017.

Fratus de Balestrini, E., Ballarin, M., Balletti, C., Buttolo, V., Gottardi, C., Guerra, F., Mander, S., Pilot, L., and Vernier, P., 2013. Survey methods for earthquake damages in the Camera degli Sposi of Mantegna (Mantova). Int. Arch. Photogramm. Remote Sens. Spatial Inf. Sci., XL-5/W2, 265-270, doi:10.5194/isprsarchives-XL-5-W2-265-2013.

Italian regulations on seismic vulnerability:

D.M. 14.01. 2008 - "Nuove Norme Tecniche per le Costruzioni";

Circular letter 9.02.2009, n.617 - Istruzioni per l'applicazione delle "Nuove Norme Tecniche per le Costruzioni", di cui al D.M. 14.01.2008;

Directive P.C.M 9.02.2011 - "Linee Guida per la valutazione e riduzione del rischio sismico del patrimonio culturale con riferimento alle Norme Tecniche per le Costruzioni di cui al D.M. 14-01-2008"

Sites:

www.riegl.co.at

www.faro.com

www.konikaminolta.eu 